\title{
Synthesis of Activated Carbon/Chitosan/Alginate Beads Powder as an Adsorbent for Methylene Blue and Methyl Violet 2B Dyes
}

\author{
Margaretha Aditya Kurnia Purnaningtyas, Sri Sudiono, and Dwi Siswanta* \\ Department of Chemistry, Faculty of Mathematics and Natural Sciences, Universitas Gadjah Mada, \\ Sekip Utara, Yogyakarta 55281, Indonesia
}

* Corresponding author:

tel: $+62-274-454188$

email:dsiswanta@ugm.ac.id

Received: August 26, 2019

Accepted: January 20, 2020

DOI: $10.22146 / \mathrm{ijc} .49026$

\begin{abstract}
The activated carbon-chitosan-alginate (KKA) beads powder was synthesized to form an adsorbent for the cationic dyes, methylene blue $(\mathrm{MB})$ and methyl violet $2 B$ (MV 2B). The aims of this research were to determine the optimum composition of KKA beads powder for the adsorption of cationic dyes and to investigate the effect of $p H$, adsorbent mass, contact time, and initial concentration of $M B$ and $M V 2 B$ dyes. $A$ desorption study was also implemented to predict the adsorption mechanisms of $M B$ and $M V 2 B$ dyes. The KKA beads powder was prepared by mixing chitosan, Na-alginate with various variation of masses $(0.6 ; 0.8 ; 1.0 ;$ and $1.2 \mathrm{~g})$ and activated carbon. The KKA beads were immersed in a $\mathrm{CaCl}_{2}$ solution. The KKA beads powder was characterized using FTIR spectroscopy and SEM. The desorption study was conducted in $\mathrm{NaCl}(0.1 \mathrm{M}$ and $1.0 \mathrm{M})$, ethanol (40 and 60\%), and pH 4 solution. The result showed that the KKA beads powder had been successfully created, with maximum adsorption capacities of $1.34 \mathrm{mmol} \mathrm{g}^{-1}$ for $M B$ and $1.23 \mathrm{mmol} \mathrm{g}^{-1}$ for $M V 2 B$. The kinetics and isotherms of $M B$ and $M V$ dyes adsorption on the KKA beads powder followed pseudo second order kinetics model and Freundlich isotherm. The desorption study showed that $60 \%$ ethanol was the most effective desorption solution for cationic dyes.
\end{abstract}

Keywords: activated carbon; alginate; chitosan; methylene blue; methyl violet $2 B$

\section{- INTRODUCTION}

The dyeing process in the textile industry produces $10-15 \%$ of the dyes released to the environment [1]. Synthetic dyes have brightness, high color sharpness, and are clearly visible even in very low concentrations [2-3]. $\mathrm{MB}$ and MV 2B are cationic synthetic dyes. The presence of synthetic dyes in the environment can disrupt the stability of the organism in the environment due to their carcinogenic, mutagenic, and toxic effects. Therefore, the removal of dyes before being released into the water is very important.

The treatment of dye waste has been carried out by various methods such as biological processes [4], electrochemistry [5], ozonation [6], oxidation [7], photocatalyst [8], membrane filtration [9], and adsorption [10-13]. Adsorption became the most popular and widely used method due to its low operational costs, simple and easy procedure, requires less energy, non- toxic effects, and because it is highly effective for the degradation of waste [10].

Activated carbon is a porous material that has potential in the removal of chemical species by adsorption [14]. The mesopores and macropores of activated carbon can be used to remove large pollutants such as dyes [15]. According to previous studies, activated carbon is able to adsorb MB [16-18] and MV 2B [3,19]. Modification of activated carbon with biopolymers such as chitosan [12] and alginate $[11,13]$ can also be used as an alternative to remove cationic dyes.

Currently, there is no report about the fabrication of a composite material consisting of activated carbon, chitosan, and alginate to be used as an adsorbent for the removal of cationic dyes. Chitosan and alginate are polycationic and polyanionic natural polymers, respectively. The combination of both polymers will form a polyelectrolyte complex (PEC) due to the 
interaction between the carboxyl groups of alginates and the amino groups of chitosan [20]. The formation of PEC enriches the active sites on the surface of the adsorbent.

Therefore, the main objective of this research was to explore the potential of activated carbon-chitosanalginate (KKA) beads powder as an adsorbent for $\mathrm{MB}$ and MV 2B dyes. The aims of the research were to determine the optimum composition of KKA beads powder, to investigate the effect of contact time and initial concentration on the adsorption of $\mathrm{MB}$ and $\mathrm{MV} 2 \mathrm{~B}$, and to study the desorption of $\mathrm{MB}$ and $\mathrm{MV} 2 \mathrm{~B}$ dyes.

\section{- EXPERIMENTAL SECTION}

\section{Materials}

Chitosan (\%DD c.a. 80\%), activated carbon (technical), sodium alginate (MW 120-190 g/mol, G/M = 1.56), and other materials of analytical grade were supplied by Merck including calcium chloride, sodium hydroxide, acetic acid, hydrochloric acid, sodium chloride, ethanol absolute, MB, and MV 2B.

\section{Instrumentation}

The equipment used in this research were $\mathrm{pH}$ meter (SI Analytics Lab 860), magnetic stirrer, shaker (Memmert), and centrifuge (Thermo Scientific SL 16R). Characterization of the functional groups of the KKA beads powder was detected by Fourier transform infrared spectroscopy (FTIR) (Prestige-21 Shimadzu) at 4000$500 \mathrm{~cm}^{-1}$ wavelength. The morphology of the KKA beads powder was characterized by Scanning Electron Microscopy (SEM) (JSM-6510LV). The concentration of dyes was analyzed by Spectrophotometer UV-Vis (Thermoscientific 20D).

\section{Procedure}

\section{Synthesis of the activated carbon/chitosan/alginate (KKA) beads powder}

Chitosan $(1 \mathrm{~g})$ in $30 \mathrm{~mL}$ of acetic acid $(2.0 \% \mathrm{v} / \mathrm{v})$ was mixed with sodium alginate $(1 \mathrm{~g})$ in $30 \mathrm{~mL}$ of acetic acid $(2.0 \% \mathrm{v} / \mathrm{v})$. After the suspension had mixed completely, activated carbon ( $1 \mathrm{~g}$ ) was added into the suspension. The suspension of KKA was stirred using a magnetic stirrer for $24 \mathrm{~h}$. Then, the KKA beads were formed by dripping the solution into a $\mathrm{CaCl}_{2}(2.5 \% \mathrm{~b} / \mathrm{v})$ solution. The KKA beads were washed, dried, and crushed into powder. The same procedure was made for the synthesis of KKA beads powder with mass variations of sodium alginate (0.6; 0.8; and $1.2 \mathrm{~g})$.

\section{The optimum composition of KKA beads powder}

The optimum composition of the KKA beads powder was determined by mixing mass variations of sodium alginate $(0.6 ; 0.8$; and $1.2 \mathrm{~g})$ during the synthesis of the powder. The resulting KKA beads powder $(20 \mathrm{mg})$ was added into $20 \mathrm{~mL}$ of MB or MV 2B dyes solution with concentration of $100 \mathrm{mg} \mathrm{L}^{-1}$ and the adsorption was carried out for $60 \mathrm{~min}$. Afterwards, the solid material was separated, and the filtrate was analyzed by spectrophotometry UV-Vis. The adsorption capacity of the adsorbent towards $\mathrm{MB}$ and MV 2B dyes were calculated using Eq. (1).

$\operatorname{Adsorption~capacity~}\left(\mathrm{q}_{\mathrm{t}}\right)=\frac{\left(\mathrm{C}_{\mathrm{o}}-\mathrm{C}_{\mathrm{t}}\right) \mathrm{V}}{\mathrm{m}}$

where $\mathrm{C}_{\mathrm{o}}\left(\mathrm{mg} \mathrm{L}^{-1}\right)$ is the initial concentration of dyes, $\mathrm{C}_{t}$ $\left(\mathrm{mg} \mathrm{L}^{-1}\right)$ is the concentration of dyes after adsorption, $\mathrm{m}$ (g) is the mass of the adsorbent, and $\mathrm{V}(\mathrm{mL})$ is the volume of the dyes.

\section{Effect of $\mathrm{pH}$}

A series of solutions containing $20 \mathrm{~mL}$ of $100 \mathrm{mg} \mathrm{L}^{-1}$ $\mathrm{MB}$ or MV 2B dyes were prepared with $\mathrm{pH}$ of $4,5,6,7$, 8, and 9. $\mathrm{pH}$ adjustment was carried out by adding $0.1 \mathrm{M}$ $\mathrm{NaOH}$ and $0.1 \mathrm{M} \mathrm{HCl}$. Into the series of dyes solution, $20 \mathrm{mg}$ of KKA beads powder with optimum composition was added as obtained from the previous experiment. Then the adsorption was carried out for $60 \mathrm{~min}$. The solid material was then separated, and the filtrate was analyzed by spectrophotometry UV-Vis.

\section{Effect of adsorbent dose}

The effect of adsorbent dose was investigated by using 10, 20, 30, 40, and $50 \mathrm{mg}$ of KKA beads powder. The varied adsorbent doses were added into $20 \mathrm{~mL}$ of $100 \mathrm{mg} \mathrm{L}^{-1} \mathrm{MB}$ or MV 2B dyes solution. The solution was adjusted to the optimum $\mathrm{pH}$ obtained from the previous experiment. Then the adsorption was carried out for $60 \mathrm{~min}$. The solid material was then separated, and the filtrated dyes were analyzed by spectrophotometry UV-Vis. 


\section{Effect of contact time}

The effect of contact time was determined within the time range of 5-180 min. The optimum adsorbent dose of the KKA beads powder obtained from the previous experiment was added into $20 \mathrm{~mL}$ of $100 \mathrm{mg} \mathrm{L}^{-1} \mathrm{MB}$ or MV 2B dyes solution at the optimum $\mathrm{pH}$. The adsorption was conducted for $5,10.15,30.45,60,90,120,150$, and $180 \mathrm{~min}$. The solid material was then separated, and the filtrated dyes were analyzed by spectrophotometry UV-Vis.

\section{Effect of initial concentration}

The optimum dose of the KKA beads powder was added into $20 \mathrm{~mL}$ of $\mathrm{MB}$ or $\mathrm{MV} 2 \mathrm{~B}$ dyes solution at optimum $\mathrm{pH}$. The effect of initial concentrations was investigated in $25,50,75,100,150,200,300,400,500,600$, 800 , and $1000 \mathrm{mg} \mathrm{L}^{-1}$. The adsorption was carried out for the duration of the optimum time as obtained from the previous experiment. The solid material was then separated, and the filtrated dyes were analyzed by spectrophotometry UV-Vis.

\section{Adsorption Selectivity of MB and MV $2 B$ dyes}

The adsorption selectivity test between MB and MV $2 \mathrm{~B}$ dyes was determined in comparison to the mole of $\mathrm{MB}$ : MV 2B dyes (1:0, 0:1, and 1:1). The adsorption was investigated in the optimum condition of $\mathrm{MB}$ or MV 2B.

\section{Study of desorption}

The process of desorption was investigated in $\mathrm{NaCl}$ ( 0.1 and $1.0 \mathrm{M}$ ), ethanol (40 and 60\%) and $\mathrm{pH} 4$ solution. The time of desorption was carried out for $1,3,18$, and $24 \mathrm{~h}$. The percentage of desorption was calculated using Eq. (2).

\%Desorption $=\frac{\mathrm{C}_{\mathrm{e}}}{\mathrm{C}_{\mathrm{o}}} \times 100 \%$

where $\mathrm{C}_{e}\left(\mathrm{mg} \mathrm{L}^{-1}\right)$ is the concentration of dyes after desorption and $\mathrm{C}_{\mathrm{o}}\left(\mathrm{mg} \mathrm{L}^{-1}\right)$ is the concentration of dyes in the adsorbent.

\section{Isotherm models for the adsorption of $M B$ and $M V 2 B$ dyes}

The isotherms for the adsorption of $\mathrm{MB}$ and MV 2B dyes were determined using two models according to Eq. (3) and (4).

Langmuir isotherm: $\frac{\mathrm{C}_{\mathrm{e}}}{\mathrm{q}_{\mathrm{e}}}=\frac{1}{\mathrm{~K}_{\mathrm{L}} \mathrm{q}_{\max }}+\frac{\mathrm{C}_{\mathrm{e}}}{\mathrm{q}_{\max }}$
Freundlich isotherm: $\ln \mathrm{q}_{\mathrm{e}}=\ln \mathrm{K}_{\mathrm{F}}+\frac{1}{\mathrm{n}} \ln \mathrm{C}_{\mathrm{e}}$

where $\mathrm{K}_{\mathrm{L}}\left(\mathrm{L} \mathrm{mg}^{-1}\right)$ is the Langmuir constant, $\mathrm{q}_{\max }\left(\mathrm{mg} \mathrm{g}^{-1}\right)$ represents the monolayer capacity, $\mathrm{K}_{\mathrm{F}}$ and $\mathrm{n}$ are Freundlich constants, $\mathrm{C}_{\mathrm{e}}\left(\mathrm{mg} \mathrm{L}^{-1}\right)$ is the equilibrium concentration, and $\mathrm{q}_{\mathrm{e}}\left(\mathrm{mg} \mathrm{g}^{-1}\right)$ is the amount adsorbed at equilibrium.

\section{Kinetics model for the adsorption of $M B$ and $M V 2 B$ dyes}

The kinetics model for the adsorption of $\mathrm{MB}$ and MV 2B dyes was determined using four models according to the following equations:

First - order kinetics model $: \ln \mathrm{C}_{\mathrm{e}}=\ln \mathrm{C}_{0}-\mathrm{k}_{1} \mathrm{t}$

Second-order kinetics model : $\frac{1}{\mathrm{C}_{\mathrm{e}}}=\frac{1}{\mathrm{C}_{0}}+\mathrm{k}_{2} \mathrm{t}$

Pseudo first - order kinetics model $: \ln \left(q_{\mathrm{e}}-\mathrm{q}_{\mathrm{t}}\right)=\ln \mathrm{q}_{\mathrm{e}}-\mathrm{k}_{1} \mathrm{t}$

Pseudo first - order kinetics model $: \frac{\mathrm{t}}{\mathrm{q}_{\mathrm{t}}}=\frac{1}{\mathrm{k}_{2} \mathrm{q}_{\mathrm{e}}{ }^{2}}+\frac{\mathrm{t}}{\mathrm{q}_{\mathrm{e}}}$

where $\mathrm{k}\left(\mathrm{min}^{-1}\right)$ is the rate constant, $\mathrm{t}(\mathrm{min})$ is time, $\mathrm{C}_{0}$ ( $\mathrm{mg} \mathrm{L}^{-1}$ ) is the initial concentration, $\mathrm{C}_{e}\left(\mathrm{mg} \mathrm{L}^{-1}\right)$ is the equilibrium concentration, and $\mathrm{q}_{\mathrm{e}}\left(\mathrm{mg} \mathrm{g}^{-1}\right)$ is the amount adsorbed at equilibrium.

\section{- RESULTS AND DISCUSSION}

\section{FTIR Spectra of KKA Beads Powder}

FTIR analysis was used to identify several characteristic functional groups of the KKA beads powder. The FTIR spectra of the KKA beads powder before and after the dyes adsorption-desorption are shown in Fig. 1. Fig. 1 shows that activated carbon has characteristic peaks at 1628, 3425, also 2855 and $2924 \mathrm{~cm}^{-1}$ due to stretching vibrations of $-\mathrm{C}=\mathrm{O},-\mathrm{OH}$, and $-\mathrm{CH}$. Modified activated carbon peaks shifted from 1628 to $1605 \mathrm{~cm}^{-1}$. This data represented the electrostatic interactions between the $-\mathrm{NH}_{3}{ }^{+}$of chitosan and $-\mathrm{COO}^{-}$ of alginates that form PEC in KKA beads powder. Additional peaks at 1400 and $1034 \mathrm{~cm}^{-1}$ are identical to stretching vibrations of $-\mathrm{CH}$ amines from chitosan structures and stretching vibrations of $-\mathrm{CO}$ from chitosan and alginate structures.

FTIR spectra after $\mathrm{MB}$ and $\mathrm{MV} 2 \mathrm{~B}$ dyes adsorption-desorption showed shifting of peaks that occurred due to the interaction between adsorbents and 


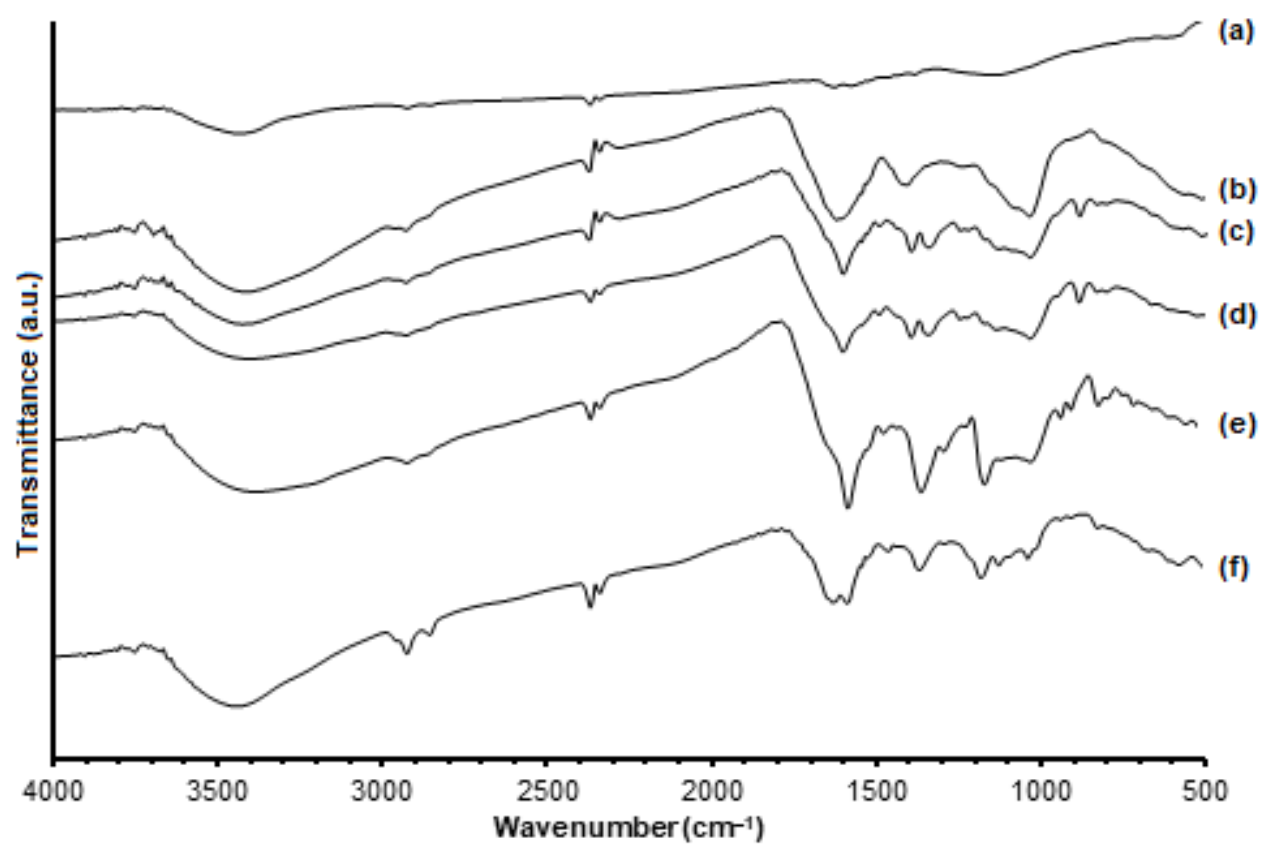

Fig 1. FTIR spectra for (a) activated carbon, (b) KKA beads powder 0.8, KKA beads powder 0.8: (c) after adsorption of $\mathrm{MB}$, (d) after desorption of MB, (e) after adsorption of MV 2B, and (f) after desorption of MV 2B, respectively.

$\mathrm{MB} / \mathrm{MV} 2 \mathrm{~B}$ dyes [12-13]. After the MB adsorption and desorption, there were new peaks at 1342 and $802 \mathrm{~cm}^{-1}$ which show stretching vibrations of $-\mathrm{N}=\mathrm{O}$ and $-\mathrm{CS}$, respectively [18]. The additional peak between 1134 to $1180 \mathrm{~cm}^{-1}$ is identical to stretching vibrations of $-\mathrm{CN}$ of the dyes on the surface of the adsorbent [21]. Decreased peak intensity at $1034 \mathrm{~cm}^{-1}$ is due to the interaction of dyes and the KKA beads powder [13].

\section{SEM Analysis of KKA Beads Powder}

The surface morphology of the KKA beads powder was characterized by SEM analysis. The SEM photograph for activated carbon and the KKA beads powder before and after adsorption-desorption of $\mathrm{MB}$ and MV 2B under the same magnifications is given in Fig. 2. Fig. 2 shows that activated carbon has an irregular surface and various pore sizes. The pore size of the KKA
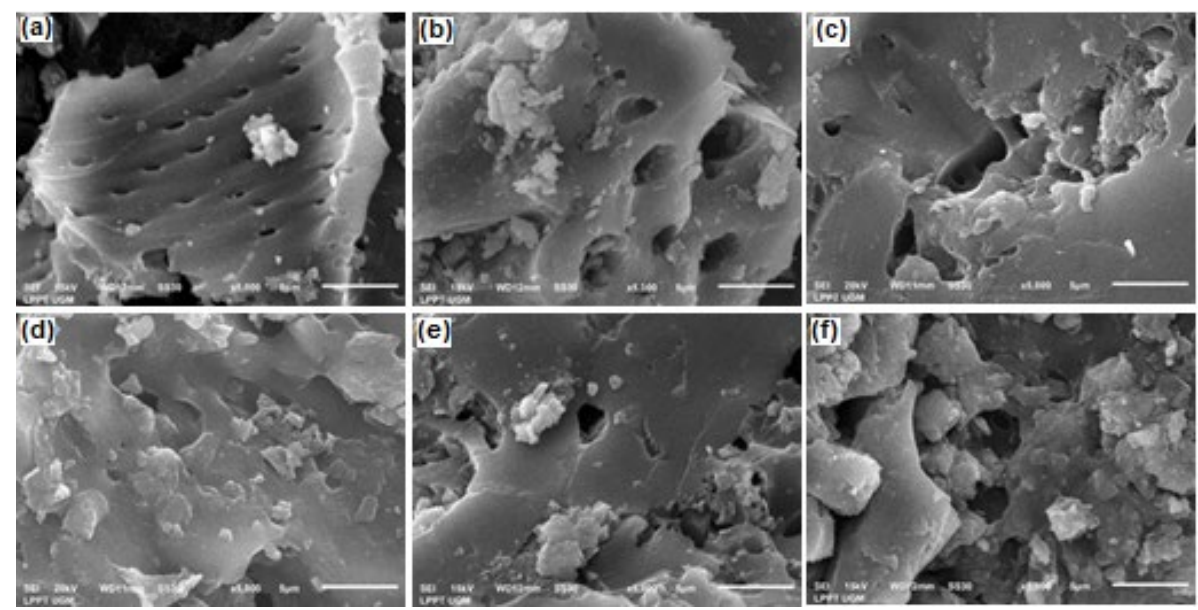

Fig 2. SEM images at 5000 magnifications for - (a) activated carbon, (b) KKA beads powder 0.8, KKA beads powder 0.8: (c) after adsorption of $\mathrm{MB}$, (d) after adsorption of $\mathrm{MV} 2 \mathrm{~B}$, (e) after desorption of $\mathrm{MB}$, and (f) after desorption of MV 2B, respectively 
beads powder looks larger than that of the activated carbon. Chemical modification with chitosan and alginate through PEC can increase the pore size of activated carbon, potentially increasing the adsorption capacity of the dyes [13].

According to Fig. 2, the adsorption of dyes caused the surface of the KAA beads powder to be rough with lumps covering the pore of the activated carbon. These lumps indicate the presence of interaction between adsorbent and adsorbate, as well as showing the adsorbates which are trapped in the pores [22]. The SEM image of the KKA beads powder after desorption with $60 \%$ ethanol also shows the rough and lumpy surface. It shows that the desorption process is also followed by the removal of the adsorbent material from the surface of the KKA beads powder.

\section{The Optimum Composition of KKA Beads Powder}

Fig. 3 shows that the adsorption capacity of dyes decreased as an increasing amount of alginate was added. The formation of the KKA beads was carried out in a solution of $\mathrm{CaCl}_{2}$ that acted as an agent to form and strengthen the physical properties of the beads. Increasing the amount of alginate increased the $-\mathrm{COO}^{-}$group and also increased the risk of the group reacting with $\mathrm{Ca}^{2+}$ during the beads formation process. This caused the amount of $-\mathrm{COO}^{-}$available to bind with dyes reduced, leading to the decrease of the adsorption capacity. The composition of the KKA beads powder that had maximum adsorption capacity was observed at $0.8 \mathrm{~g}$ alginate with $0.284 \mathrm{mmol} \mathrm{g}^{-1}(\mathrm{MB})$ and $0.213 \mathrm{mmol} \mathrm{g}^{-1}$ (MV 2B).

\section{Effect of $\mathrm{pH}$}

The effect of $\mathrm{pH}$ on the dye adsorption of the KKA beads powder was studied at the $\mathrm{pH}$ range of $4-9$. The relationship curve between the amount of dyes adsorbed and various $\mathrm{pH}$ is shown in Fig. 4 . Fig. 4 shows that the dyes adsorption capacity increased along with the increase in $\mathrm{pH}$. The KKA beads powder adsorption capacity tended to decrease after $\mathrm{pH}$ 7. The maximum adsorption capacity was observed at $\mathrm{pH}$ 7. Therefore, $\mathrm{pH}$ 7 was selected as the optimal $\mathrm{pH}$ for the dyes removal from aqueous solution using KKA beads powder. The adsorption capacity of the KKA beads powder at $\mathrm{pH} 7$ was $0.285 \mathrm{mmol} \mathrm{g}^{-1}(\mathrm{MB})$ and $0.216 \mathrm{mmol} \mathrm{g}^{-1}$ (MV 2B).

Chitosan in acidic medium will be protonated to $-\mathrm{NH}_{3}{ }^{+}$. The carboxylic group of alginate will maintain its protons thereby reducing the possibility of bonding with other positively charged ions [23]. The presence of an excess amount of free protons in an acidic solution competes with the dyes molecules for adsorption sites on the surface of the adsorbent [24]. At $\mathrm{pH}$ close to neutral, the dominant form of chitosan is $-\mathrm{NH}_{2}$. The presence of $-\mathrm{NH}_{2},-\mathrm{OH}$, and $-\mathrm{COO}^{-}$on the surface of the KKA beads powder can increase interactions with cationic dyes, so the capacity of adsorption increases. Adsorption capacity tends to decrease at basic medium, despite the high availability of $-\mathrm{COO}^{-}$on the surface of the adsorbent. This is due to the interaction between $\mathrm{OH}^{-}$ ions and cationic dyes in the solution. [25].

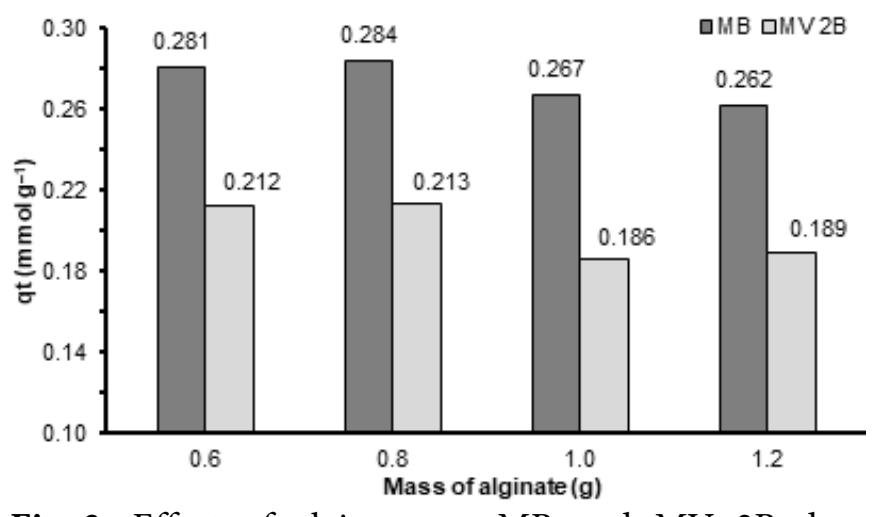

Fig 3. Effect of alginate on $M B$ and $M V 2 B$ dyes adsorption onto the KKA beads powder

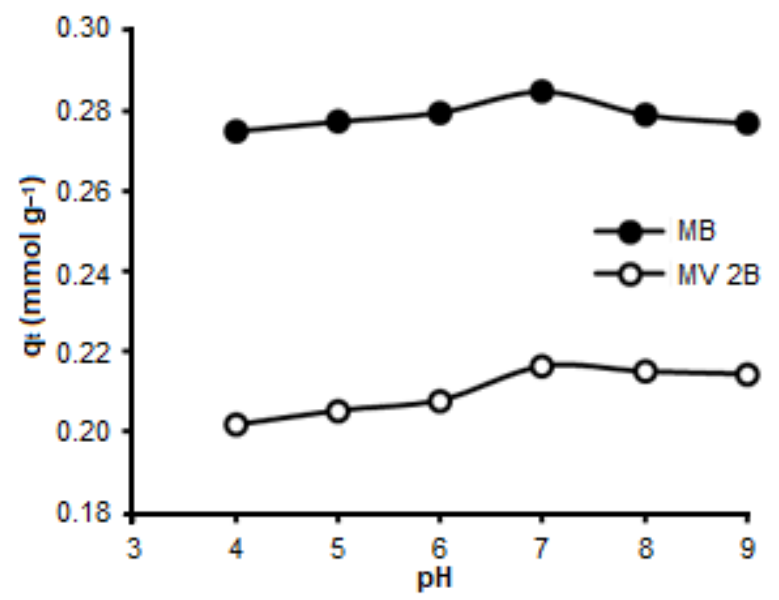

Fig 4. Effect of $\mathrm{pH}$ on $\mathrm{MB}$ and $\mathrm{MV} 2 \mathrm{~B}$ dyes adsorption onto the KKA beads powder 


\section{Effect of Adsorbent Dosage}

Fig. 5 shows the adsorption capacity and removal percentage of dyes against the adsorbent dosage. The percentage of adsorption increased with increasing amount of adsorbent dosage. As the adsorbent dose increase, the amount of active sites on the surface of the adsorbent also increases, so more dye molecules can adsorb to the surface of the adsorbent. Higher adsorbent dosage however, caused the adsorbent to aggregate reducing the surface area thus decreasing the adsorption capacity [25]. The KKA beads powder optimum dosage in this study was $30 \mathrm{mg}$ with an adsorption percentage of more than $80 \%$ for both $\mathrm{MB}$ and MV $2 \mathrm{~B}$.

\section{Effect of Contact Time}

Fig. 6 shows the effect of contact time on the adsorption capacity of the KKA beads powder towards dyes. High adsorption capacity occurs at the beginning of the contact time because the active sites in the adsorbent is still empty, causing the dye molecules to be easily attached to the surface of the adsorbent. The adsorption capacity of the adsorbent towards the MV 2B dye increased gradually with increasing contact time, but the adsorption capacity towards the MB dye decreased after $60 \mathrm{~min}$. The decrease in adsorption capacity is due to the decrease in the number of active sites on the adsorbent.

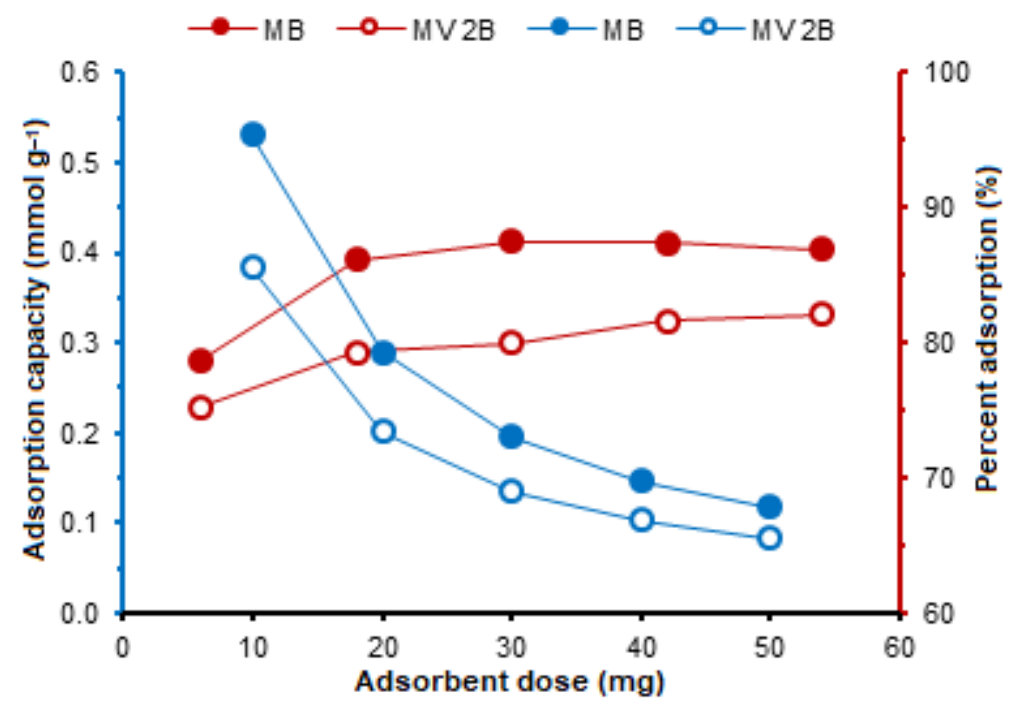

Fig 5. Effect of adsorbent dose of KKA beads powder on adsorption of MB and MV 2B dyes

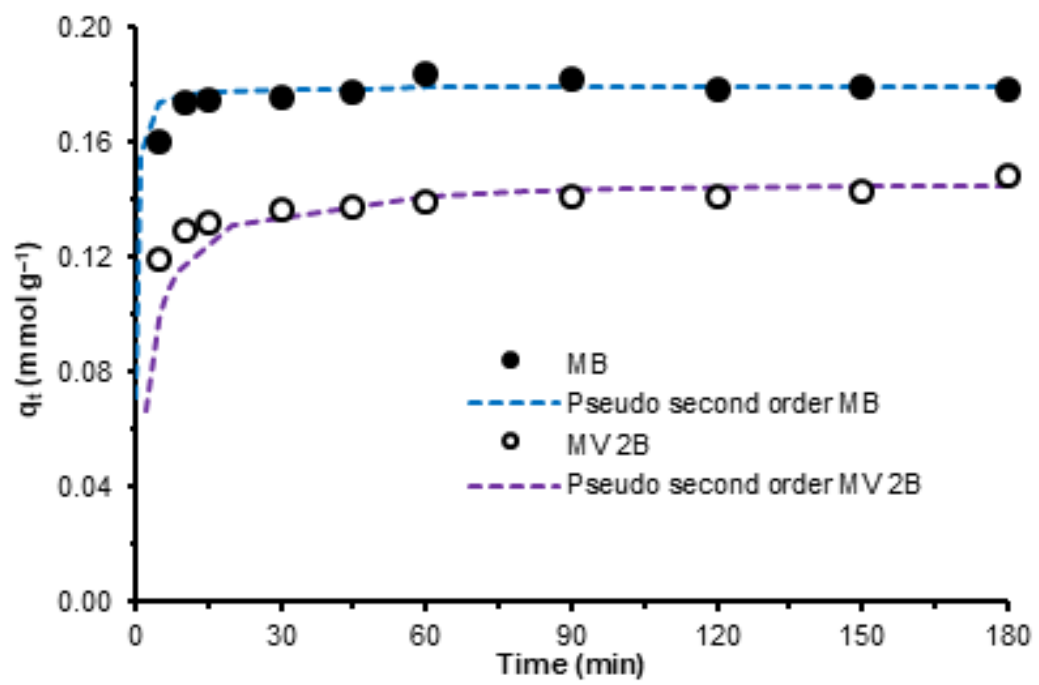

Fig 6. Effect of time on adsorption of MB and MV 2B dyes onto the KKA beads powder 
The kinetics model for the KKA beads powder was described using four models, which consisted of the firstorder, second-order, pseudo first-order, and pseudo second-order kinetic models. The kinetics data for the KKA beads powder in the various models are shown in Table 1 . The $\mathrm{R}^{2}$ value in the pseudo second-order kinetics model was closer to one, so it can be assumed that the pseudo second-order kinetics model best expressed the adsorption of the KKA beads powder. Theoretically, the pseudo second-order kinetics model describes the adsorption of more than one active sites of the adsorbent.

The dyes had $0.115 \mathrm{mg} \mathrm{g}^{-1} \min ^{-1}(\mathrm{MB})$ and $0.007 \mathrm{mg} \mathrm{g}^{-1} \min ^{-1}$ (MV 2B) of $\mathrm{k}$ value. These results illustrate that the adsorption rate of the $\mathrm{MB}$ dye was greater than the adsorption rate of MV 2B. Smaller molecule size are more easily distributed, thus equilibrium would be achieved faster [26]. The MB dye have smaller molecular sizes compared to the MV 2B dye, which explains why higher adsorption rate of $\mathrm{MB}$ dye had a larger adsorption rate.

\section{Effect of Initial Concentration}

Fig. 7 shows that the adsorption capacity of the dye increased with increasing initial concentration. The adsorption limit which describes the saturation of the adsorbent against the adsorbate is not visible. The chance of the adsorbate interaction with the activated site of the adsorbent will increase with an increasing number of dye molecules in the solution. In this study, the maximum adsorption capacity of the KKA beads was

Table 1. Adsorption kinetics parameters of the adsorption on MB and MV 2B dyes onto the KKA beads powder

\begin{tabular}{llcl}
\hline Kinetics model & Parameter & MB & MV 2B \\
\hline Molecular weight $\left(\mathrm{g} \mathrm{mol}^{-1}\right)$ & & 319.86 & 393.96 \\
$\mathrm{q}_{\mathrm{e}}$ experiment $\left(\mathrm{mmol} \mathrm{g}^{-1}\right)$ & & 0.183 & 0.148 \\
First-order & $\mathrm{R}^{2}$ & 0.2953 & 0.8316 \\
& $\mathrm{k}_{1}^{\prime}\left(\mathrm{min}^{-1}\right)$ & 0.001 & 0.004 \\
Second-order & $\mathrm{R}^{2}$ & 0.2845 & 0.8817 \\
Pseudo first-order & $\mathrm{k}_{2}^{\prime}\left(\mathrm{min}^{-1}\right)$ & 0.026 & 0.083 \\
& $\mathrm{R}^{2}$ & 0.4367 & 0.9435 \\
Pseudo second-order & $\mathrm{k}_{1}\left(\mathrm{~min}^{-1}\right)$ & 0.007 & 0.061 \\
& $\mathrm{q}_{\mathrm{e}}{\mathrm{cal}\left(\mathrm{mmol} \mathrm{g}^{-1}\right)}^{\mathrm{R}^{2}}$ & 0.011 & 0.020 \\
& $\mathrm{k}_{2}\left(\mathrm{~g} \mathrm{mmol}^{-1} \mathrm{~min}^{-1}\right)$ & 0.9998 & 0.9991 \\
& $\mathrm{k}_{2}\left(\mathrm{~g} \mathrm{mg}^{-1} \mathrm{~min}^{-1}\right)$ & 36.8 & 2.79 \\
& $\mathrm{q}_{\mathrm{e}} \mathrm{cal}\left(\mathrm{mmol} \mathrm{g}^{-1}\right)$ & 0.115 & 0.007 \\
& & 0.179 & 0.147 \\
\hline
\end{tabular}

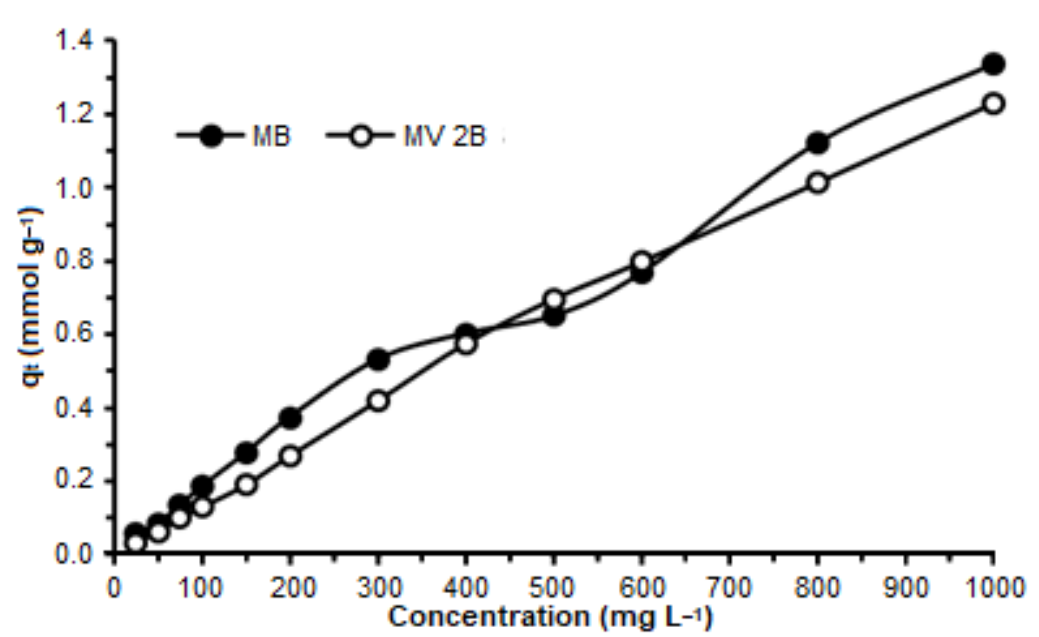

Fig 7. Effect of concentration on adsorption of MB and MV 2B dyes on the KKA beads powder 
obtained at $1000 \mathrm{mg} \mathrm{L}^{-1}$, with $1.34 \mathrm{mg} \mathrm{g}^{-1}(\mathrm{MB})$ and $1.23 \mathrm{mg} \mathrm{g}^{-1}$ (MV 2B) adsorption capacity.

The adsorption isotherms studied in this research are Langmuir and Freundlich isotherms. A summary of the adsorption isotherms calculation can be seen in Table 2. Table 2 shows that the $\mathrm{R}^{2}$ value in the Freundlich isotherm is closer to one compared to the Langmuir isotherm which means that the MB and MV 2B dye adsorption on the KKA beads powder follow the Freundlich isotherm. Adsorption of MB dyes with zeoliteactivated carbon/chitosan beads [12] and activatedalginate beads [13] also followed the Freundlich isotherm. The Freundlich isotherm describes the process of adsorption on heterogeneous surfaces. The heterogeneity factor $(1 / n)$ is a characteristic of the Freundlich model. In this study, $\mathrm{n}$ values were 1.64 (MB) and 1.16 (MV 2B). The higher $n$ value represents the higher heterogeneity of the site on the adsorbent.

\section{Selectivity Adsorption of MB and MV 2B Dyes}

Fig. 8 shows that the maximum adsorption of dyes are smaller if they are in a multicomponent solution, which proves that there is a competitive effect between the dyes. Under optimum conditions of $\mathrm{MB}$ adsorption, the presence of $\mathrm{MV} 2 \mathrm{~B}$ reduced $\mathrm{MB}$ adsorption by $11.7 \%$. Meanwhile, under the optimum conditions of MV 2B dye adsorption, the presence of $\mathrm{MB}$ reduced MV $2 \mathrm{~B}$ adsorption by $12.3 \%$. These results indicate that the reduction of $\mathrm{MV} 2 \mathrm{~B}$ adsorption is greater in multicomponent solutions. In multicomponent solutions, smaller molecules will occupy the pores in the adsorbent structure first [27]. The MB dye have a smaller molecular weight compared to $\mathrm{MV} 2 \mathrm{~B}$ causing the molecules of the MB dye to fill the pores of the adsorbent earlier than the MV 2B dye.

Table 2. The Langmuir and Freundlich isotherm parameters for MB and MV 2B dyes

\begin{tabular}{llcc}
\hline Isotherms model & Parameter & $\mathrm{MB}$ & $\mathrm{MV} 2 \mathrm{~B}$ \\
\hline $\mathrm{q}_{\mathrm{e}}$ experiment $\left(\mathrm{mmol} \mathrm{g}^{-1}\right)$ & & 1.34 & 1.23 \\
Langmuir isotherm & $\mathrm{q}_{\max }\left(\mathrm{mmol} \mathrm{g}^{-1}\right)$ & 1.36 & 2.42 \\
& $\mathrm{~K}_{\mathrm{L}}\left(\mathrm{L} \mathrm{mol}^{-1}\right)$ & 3135 & 1552 \\
& $\mathrm{E}(\mathrm{KJ} / \mathrm{mol})$ & 20.1 & 18.3 \\
Freundlich isotherm & $\mathrm{R}^{2}$ & 0.8212 & 0.8789 \\
& $\mathrm{~K}_{\mathrm{F}}$ & 1.17 & 2.14 \\
& $\mathrm{n}$ & 1.64 & 1.16 \\
& $\mathrm{R}^{2}$ & 0.9035 & 0.9820 \\
\hline
\end{tabular}
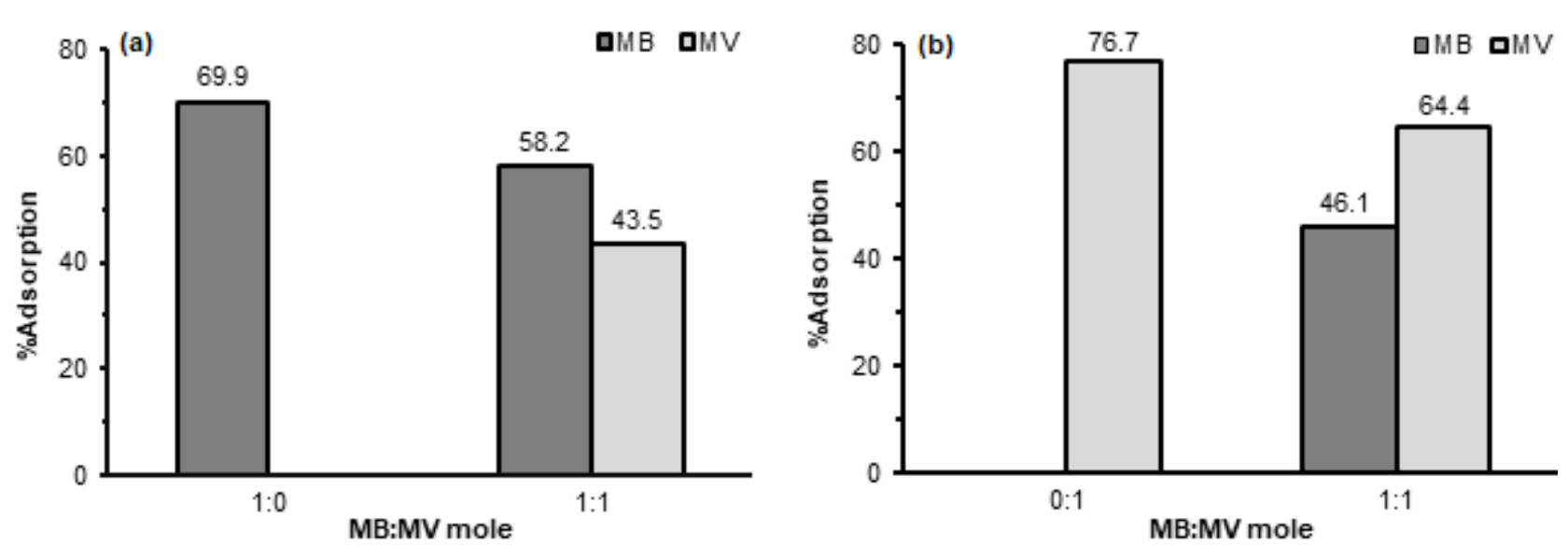

Fig 8. Effect of percentage adsorption of $M B$ and $M V 2 B$ dyes under optimum conditions of (a) $M B$ and (b) $M V 2 B$ adsorption 


\section{MB and MV 2B Dyes Adsorption}

Table 3 shows that activated carbon has adsorption capacities of $0.151 \mathrm{mmol} \mathrm{g}^{-1}(\mathrm{MB})$ and $0.171 \mathrm{mmol} \mathrm{g}^{-1}$ (MV 2B) under optimum conditions, while the adsorption capacities of the KKA beads powder are $1.34 \mathrm{mmol} \mathrm{g}^{-1}$ and $1.23 \mathrm{mmol} \mathrm{g}^{-1}$ for $\mathrm{MB}$ and MV 2B, respectively. The results showed that the adsorption ability of activated carbon after modification into KKA beads powder increased by 787 and $621 \%$ for MB and MV 2B dyes, respectively. The increased adsorption ability of the activated carbon is due to the presence of activated sites on the surface of the adsorbent from chitosan and alginate modification.

\section{Desorption Study}

Desorption solution $(\mathrm{NaCl})$ was found to have an influence in the process of releasing cationic dyes $-\mathrm{N}^{+}\left(\mathrm{CH}_{3}\right)_{2}$ (MB) and $-\mathrm{N}^{+} \mathrm{HCH}_{3}$ (MV 2B) from the adsorbent. The strength of $\mathrm{Na}^{+}$ions was able to release the electrostatic cationic dyes which had been bound to the KKA beads powder. The greater the amount of $\mathrm{Na}^{+}$ions in the solution, the greater amount of $\mathrm{MB}$ and $\mathrm{MV} 2 \mathrm{~B}$ molecules that was released. $\mathrm{pH} 4$ solution was used as the medium for desorption because it has an acidic strength that can protonate the activated site of chitosan from $-\mathrm{NH}_{2}$ to $-\mathrm{NH}_{3}{ }^{+}$. Protonated amino groups was able to increase the hydrophility of the adsorbent causing the MB or MV 2B dyes to be released. Ethanol solution in water can also act as a medium of desorption because it can attract MB or MV 2B dyes through hydrogen bonds and hydrophobic interactions [31].

Fig. 9 shows that prolonging the desorption time increased the amount of $\mathrm{MB}$ and MV 2B released from the adsorbent. The desorption order for MB and MV 2B dyes were $60 \%$ ethanol $>\mathrm{pH} 4$ solution $>40 \%$ ethanol $>$ $1.0 \mathrm{M} \mathrm{NaCl}>0.1 \mathrm{M} \mathrm{NaCl}$. Therefore, $60 \%$ ethanol solution was the most effective desorption medium. This points to the tendency for hydrogen bonds and hydrophobic interactions. The existence of double bonds and benzene rings in the structure of dyes that are hydrophobic gives the possibility that hydrophobic interactions will be more dominant than electrostatic interactions [28].

The percentage of desorption for MB and MV 2B dyes in various solvents were less than $22 \%$. This is likely because only the dye molecules on the surface of the adsorbent were able to be released. The porous structure of the KKA beads powder caused the adsorbed dyes to be trapped and difficult to escape. Similarly, MB desorption studies on carbon monolith (CM) adsorbents using ethanol were only able to adsorb $\mathrm{MB}$ dyes attached to the CM surfaces, not in macro and mesoporous adsorbent structures [32].

Table 3. Comparison of MB and MV 2B dye adsorption capacity in various adsorbents

\begin{tabular}{|c|c|c|c|c|c|c|c|c|c|}
\hline \multirow{2}{*}{ Adsorbent } & \multirow{2}{*}{ Dyes } & \multicolumn{2}{|c|}{ Capacity adsorption } & \multirow{2}{*}{$\mathrm{pH}$} & \multirow{2}{*}{$\begin{array}{l}\text { Mass } \\
(\mathrm{mg})\end{array}$} & \multirow{2}{*}{$\begin{array}{l}\text { Time } \\
(\min )\end{array}$} & \multirow{2}{*}{$\begin{array}{l}\text { Concentration } \\
\qquad\left(\mathrm{mg} \mathrm{L}^{-1}\right)\end{array}$} & \multirow{2}{*}{$\begin{array}{l}\text { Isotherm } \\
\text { model }\end{array}$} & \multirow{2}{*}{ Reference } \\
\hline & & $\mathrm{mmol} \mathrm{g}^{-1}$ & $\mathrm{mg} \mathrm{g}^{-1}$ & & & & & & \\
\hline \multirow[t]{2}{*}{ Activated carbon } & $\mathrm{MB}$ & 0.151 & 48.2 & 7 & 30 & 60 & 1000 & Freundlich & This work \\
\hline & MV 2B & 0.171 & 67.2 & 7 & 30 & 180 & 1000 & Freundlich & \\
\hline \multirow[t]{2}{*}{ KAA beads powder } & $\mathrm{MB}$ & 1.34 & 428 & 7 & 30 & 60 & 1000 & Freundlich & This work \\
\hline & MV 2B & 1.23 & 484 & 7 & 30 & 180 & 1000 & Freundlich & \\
\hline $\begin{array}{l}\text { Activated carbon } \\
\text { sunflower seed hulls }\end{array}$ & MV 2B & 0.253 & 92.6 & 4.5 & 30 & 105 & 300 & Freundlich & {$[3]$} \\
\hline $\begin{array}{l}\text { Activated carbon- } \\
\text { alginate beads }\end{array}$ & $\mathrm{MB}$ & 0.719 & 230 & 9.5 & 10 & 1200 & 100 & Freundlich & {$[13]$} \\
\hline Composite $\mathrm{HNT}-\mathrm{Fe}_{3} \mathrm{O}_{4}$ & MV 2B & 0.052 & 20.4 & 7 & 15 & 360 & 90 & Langmuir & {$[25]$} \\
\hline Activated carbon & $\mathrm{MB}$ & 2.39 & 742 & 7 & 25 & 1440 & 3000 & Langmuir & {$[28]$} \\
\hline Activated carbon-clay & $\mathrm{MB}$ & 0.560 & 179 & 9 & 20 & 1560 & 400 & Langmuir & [29] \\
\hline \multirow[t]{2}{*}{ Polyglycerol magnetic gel } & $\mathrm{MB}$ & 1.44 & 459 & 7 & 20 & 120 & 1600 & Langmuir & {$[30]$} \\
\hline & MV 2B & 1.01 & 400 & 7 & 20 & 120 & 2000 & Langmuir & \\
\hline
\end{tabular}



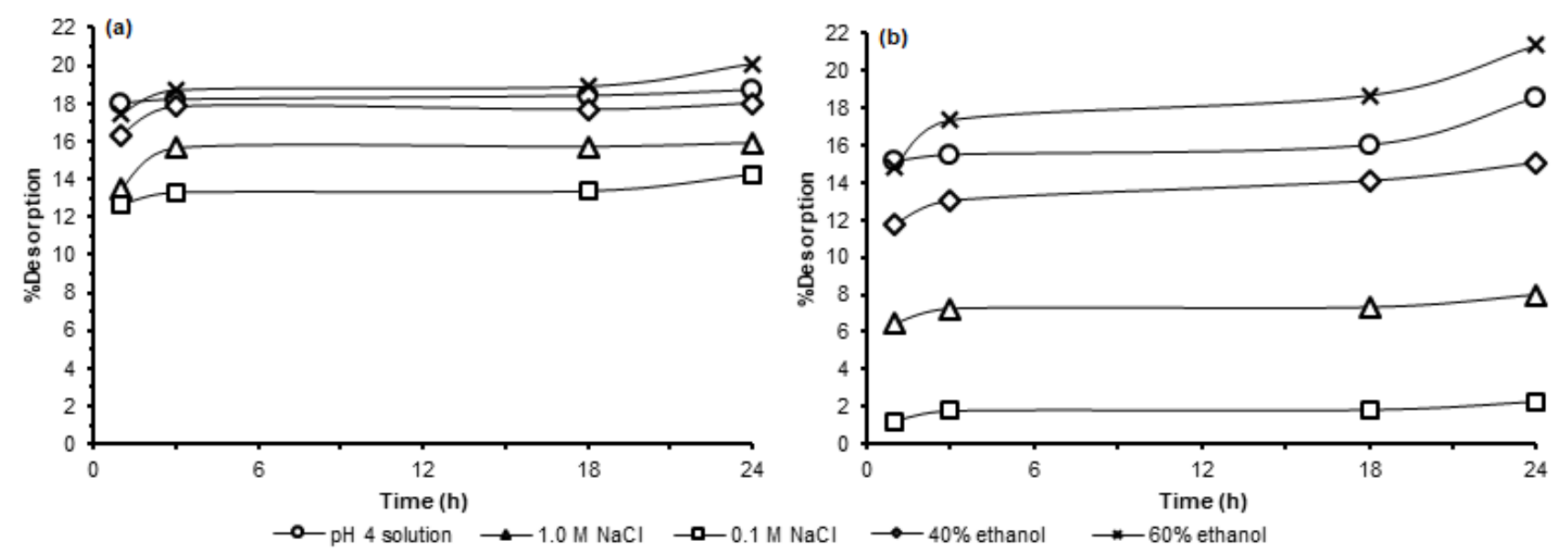

Fig 9. Percentage of desorption for (a) MB and (b) MV 2B dyes

\section{- CONCLUSION}

The optimum adsorbent composition for adsorption of $\mathrm{MB}$ and MV 2B dyes was found in KKA beads powder with $0.8 \mathrm{~g}$ of alginate. The optimum contact time was $60 \mathrm{~min}$ for the MB dye and $180 \mathrm{~min}$ for MV 2B. Both dyes followed a pseudo second-order kinetics model with an adsorption rate of $0.115 \mathrm{~g} \mathrm{mg}^{-1} \mathrm{~min}^{-1}$ for $\mathrm{MB}$ and $0.007 \mathrm{~g}$ $\mathrm{mg}^{-1} \mathrm{~min}^{-1}$ for MV 2B. The optimum initial concentration for both dyes was $1000 \mathrm{mg} \mathrm{L}^{-1}$. Both dyes followed the Freundlich isotherm with $\mathrm{K}_{\mathrm{F}}$ and $\mathrm{n}$ values of 1.17 and 1.64, respectively for $\mathrm{MB}$, and 2.14 and 1.16 respectively for MV 2B. The most effective desorption medium for MB and MV 2B dyes in the KKA beads powder was $60 \%$ ethanol.

\section{- ACKNOWLEDGMENTS}

This research was financially supported by the Master Thesis Research Program of the Director General of Higher Education, Ministry of Education and Culture, Republic of Indonesia (contract number 2858/UN1.DIT LIT/DIT-LIT/LT/2019).

\section{- REFERENCES}

[1] Zhou, L., Huang, J., He, B., Zhang, F., and Li, H., 2014, Peach gum for efficient removal of methylene blue and methyl violet dyes from aqueous solution, Carbohydr. Polym., 101, 574-581.

[2] Aksu, Z., 2005, Application of biosorption for the removal of organic pollutants: A review, Process Biochem., 40 (3-4), 997-1026.
[3] Hameed, B.H., 2008, Equilibrium and kinetic studies of methyl violet sorption by agricultural waste, J. Hazard. Mater., 154 (1-3), 204-212.

[4] Lucas, M.S., Dias, A.A., Sampaio, A., Amaral, C., and Peres, J.A., 2007, Degradation of a textile reactivated Azo dye by a combined chemicalbiological process: Fenton's reagent-yeast, Water Res., 41 (5), 1103-1109.

[5] Orts, F., del Río, A.I., Molina, J., Bonastre, J., and Cases, F., 2018, Electrochemical treatment of real textile wastewater: Trichromy Procion $\mathrm{HEXL}^{\oplus}, J$. Electroanal. Chem., 808, 387-394.

[6] Al jibouri, A.K.H., Wu, J., and Upreti, S.R., 2015, Continuous ozonation of methylene blue in water, J. Water Process Eng., 8, 142-150.

[7] Mohod, A.V., Hinge, S.P., Raut, R.S., Bagal, M.V., and Pinjari, D., 2018, Process intensified removal of methyl violet $2 \mathrm{~B}$ using modified cavity-bubbles oxidation reactor, J. Environ. Chem. Eng., 6 (1), 574-582.

[8] Liu, H., Zhong, L., Govindaraju, S., and Yun, K., 2019, $\mathrm{ZnO}$ rod decorated with Ag nanoparticles for enhanced photocatalytic degradation of methylene blue, J. Phys. Chem. Solids, 129, 46-53.

[9] Zhao, R., Li, Y., Sun, B., Chao, S., Li, X., Wang, C., and Zhu, G., 2019, Highly flexible magnesium silicate nanofibrous membranes for effective removal of methylene blue from aqueous solution, Chem. Eng. J., 359, 1603-1616. 
[10] Rafatullah, M., Sulaiman, O., Hashim, R., and Ahmad, A., 2010, Adsorption of methylene blue on low-cost adsorbents: A review, J. Hazard. Mater., 177 (1-3), 70-80.

[11] Hassan, A.F., Abdel-Mohsen, A.M., and Fouda, M.M.G., 2014, Comparative study of calcium alginate, activated carbon, and their composite beads on methylene blue adsorption, Carbohydr. Polym., 102, 192-198.

[12] Khanday, W.A., Asif, M., and Hameed, B.H., 2017, Cross-linked beads of activated oil palm ash zeolite/chitosan composite as a bio-adsorbent for the removal of methylene blue and acid blue 29 dyes, Int J. Biol. Macromol., 95, 895-902.

[13] Nasrullah, A., Bhat, A.H., Naeem, A., Isa, M.H., and Danish, M., 2018, High surface area mesoporous activated carbon-alginate beads for efficient removal of methylene blue, Int. J. Biol. Macromol., 107 (Part B), 1792-1799.

[14] Corcho-Corral, B., Olivares-Marín, M., FernándezGonzález, C., Gómez-Serrano, V., and MacíasGarcía, A., 2006, Preparation and textural characterisation of activated carbon from vine shoots (Vitis vinifera) by $\mathrm{H}_{3} \mathrm{PO}_{4}$-Chemical activation, Appl. Surf. Sci., 252 (17), 5961-5966.

[15] Gao, Y., Yue, Q., Xu, S., and Gao, B., 2015, Activated carbons with well-developed mesoporosity prepared by activation with different alkali salts, Mater. Lett., $146,34-36$.

[16] Hameed, B.H., Din, A.T.M., and Ahmad, A.L., 2007, Adsorption of methylene blue onto bamboo-based activated carbon: Kinetics and equilibrium studies, $J$. Hazard. Mater., 141 (3), 819-825.

[17] Li, W., Yue, Q., Tu, P., Ma, Z., Gao, B., Li, J., and Xu, X., 2011, Adsorption characteristics of dyes in columns of activated carbon prepared from paper mill sewage sludge, Chem. Eng. J., 178, 197-203.

[18] Pathania, D., Sharma, S., and Singh, P., 2017, Removal of methylene blue by adsorption onto activated carbon developed from Ficus carica bast, Arabian J. Chem., 10 (Suppl. 1), S1445-S1451.

[19] Chafidz, A., Astuti, W., Augustia, V., Novira, D.T., and Rofiah, N., 2018, Removal of methyl violet dye via adsorption using activated carbon prepared from Randu sawdust (Ceiba pentandra), IOP Conf. Ser.: Earth Environ. Sci., 167, 012013.

[20] Wasupalli, G.K., and Verma, D., 2018, Molecular interactions in self-assembled nano-structures of chitosan-sodium alginate based polyelectrolyte complexes, Int. J. Biol. Macromol., 114, 10-17.

[21] Xu, R.K., Xiao, S.C., Yuan, J.H., and Zhao, A.Z., 2011, Adsorption of methyl violet from aqueous solutions by the biochars derived from crop residues, Bioresour. Technol., 102 (22), 10293-10298.

[22] Nitayaphat, W., 2014, Utilization of chitosan/bamboo charcoal composite as reactivated dye adsorbent, Chiang Mai J. Sci., 41 (1), 174-183.

[23] Vijaya, Y., Popuri, S.R., Boddu, V.M., and Krishnaiah, A., 2008, Modified chitosan and calcium alginate biopolymer sorbents for removal of nickel (II) through adsorption, Carbohydr. Polym., 72 (2), 261-271.

[24] Li, P., Su, Y.J., Wang, Y., Liu, B., and Sun, L.M., 2010, Bioadsorption of methyl violet from aqueous solution onto Pu-erh tea powder, J. Hazard. Mater., 179 (1-3), 43-48.

[25] Bonetto, L.R., Ferrarini, F., de Marco, C., Crespo, J.S., Guégan, R., and Giovanela, M., 2015, Removal of methyl violet $2 \mathrm{~B}$ dye from aqueous solution using a magnetic composite as an adsorbent, J. Water Process Eng., 6, 11-20.

[26] Chiou, M.S., and Chuang, G.S., 2006, Competitive adsorption of dye metanil yellow and RB15 in acid solutions on chemically cross-linked chitosan beads, Chemosphere, 62 (5), 731-740.

[27] Noroozi, B., and Sorial, G.A., 2013, Applicable models for multi-component adsorption of dyes: A review, J. Environ. Sci., 25 (3), 419-429.

[28] Iriarte-Velasco, U., Chimeno-Alanís, N., GonzálezMarcos, M.P., and Álvarez-Uriarte, J.I., 2011, Relationship between thermodynamic data and adsorption/desorption performance of acid and basic dyes onto activated carbons, J. Chem. Eng. Data, 56 (5), 2100-2109.

[29] Marrakchi, F., Bouaziz, M., and Hameed, B.H., 2017, Activated carbon-clay composite as an 
effective adsorbent from the spent bleaching sorbent of olive pomace oil: Process optimization and adsorption of acid blue 29 and methylene blue, Chem. Eng. Res. Des., 128, 221-230.

[30] Song, Y., Duan, Y., and Zhou, L., 2018, Multicarboxylic magnetic gel from hyperbranched polyglycerol formed by thiol-ene photopolymerization for efficient and selective adsorption of methylene blue and methyl violet dyes, J. Colloid Interface Sci.,
529, 139-149.

[31] Samiey, B., and Ashoori, F., 2012, Adsorptive removal of methylene blue by agar: Effects of $\mathrm{NaCl}$ and ethanol, Chem. Cent. J., 6, 14.

[32] He, X., Male, K.B., Nesterenko, P.N., Brabazon, D., Paull, B., and Luong, J.H.T., 2013, Adsorption and desorption of methylene blue on porous carbon monoliths and nanocrystalline cellulose, ACS Appl. Mater. Interfaces, 5, 8796-8804. 